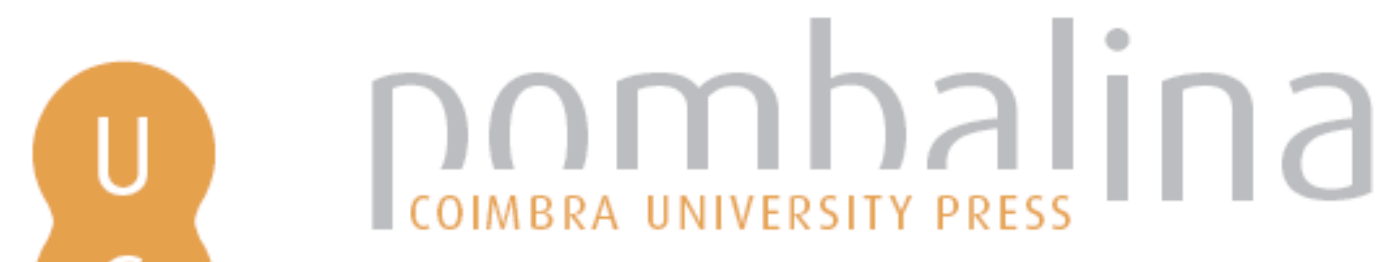

\title{
A Universidade de Salamanca e Portugal no período barroco
}

Autor(es): $\quad$ Marcos de Diós, Ángel

Publicado por: Imprensa da Universidade de Coimbra; Ediciones Universidad

URL

persistente: URI:http://hdl.handle.net/10316.2/31506

DOI: $\quad$ DOI:http://dx.doi.org/10.14195/978-989-26-0245-5_4

Accessed : $\quad$ 26-Apr-2023 03:41:39

A navegação consulta e descarregamento dos títulos inseridos nas Bibliotecas Digitais UC Digitalis, UC Pombalina e UC Impactum, pressupõem a aceitação plena e sem reservas dos Termos e Condições de Uso destas Bibliotecas Digitais, disponíveis em https://digitalis.uc.pt/pt-pt/termos.

Conforme exposto nos referidos Termos e Condições de Uso, o descarregamento de títulos de acesso restrito requer uma licença válida de autorização devendo o utilizador aceder ao(s) documento(s) a partir de um endereço de IP da instituição detentora da supramencionada licença.

Ao utilizador é apenas permitido o descarregamento para uso pessoal, pelo que o emprego do(s) título(s) descarregado(s) para outro fim, designadamente comercial, carece de autorização do respetivo autor ou editor da obra.

Na medida em que todas as obras da UC Digitalis se encontram protegidas pelo Código do Direito de Autor e Direitos Conexos e demais legislação aplicável, toda a cópia, parcial ou total, deste documento, nos casos em que é legalmente admitida, deverá conter ou fazer-se acompanhar por este aviso.

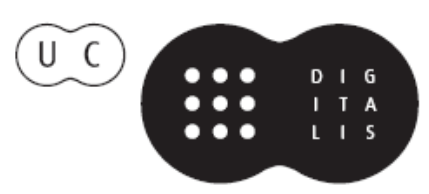


Marta Teixeira Anacleto

Sara Augusto

Zulmira Santos

Coordenação

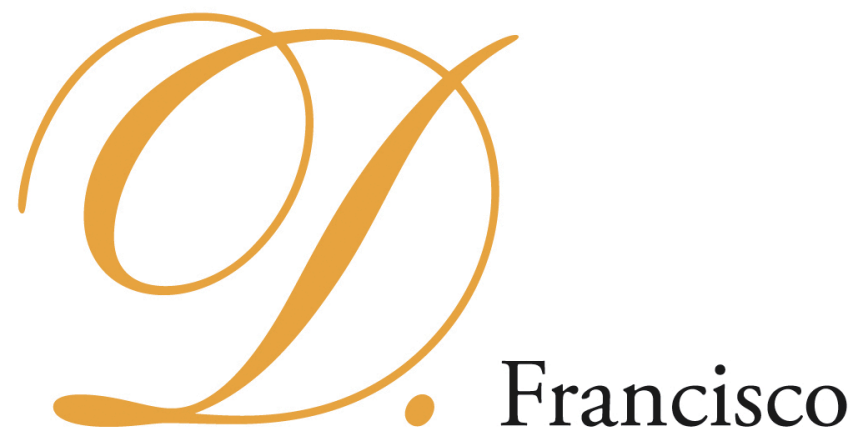

Manuel de Melo e o

Barroco Peninsular 


\title{
EDIĈ̣̃O
}

Imprensa da Universidade de Coimbra Ediciones Universidad Salamanca

\section{COORDENAÇÃo EDITORIAL}

Imprensa da Universidade de Coimbra

URL: http://www.uc.pt/imprensa_uc

Vendas online: http://www.livrariadaimprensa.com

\section{CONCEPÇÃO GRÁFICA}

António Barros

\section{REVISÃO TEXTO}

Sara Augusto

\author{
Pré-Impressão, Impressão e ACABamento \\ www.artipol.net
}

\section{IS B N}

978-989-26-0044-4 (Portugal)

978-84-7800-194-1 (Espanha)

DEPósito LEGAL

$311680 / 10$

OBRA PUBlicada COM O APOIO DE:

FCT Fundação para a Ciência e a Tecnologia

MINISTÉRIO DA CIÊNCIA, TECNOLOCIA E ENSINO SUPERIOR Portugal

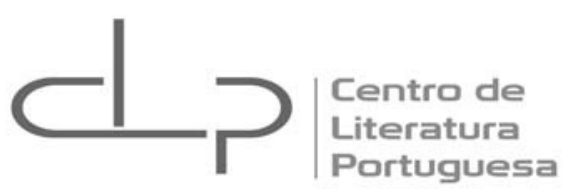

A presente publicação insere-se no Grupo "Poéticas" (coordenação de Marta Teixeira Anacleto) do Centro de Literatura Portuguesa, Unidade de I\&D financiada pela Fundação para a Ciência e a Tecnologia, ao abrigo do Programa Operacional Ciência e Inovação 2010.

(C) Agosto 2010

IMPRENSA DA UNIVERSIDADE DE COIMBRA

EDICIONES UNIVERSIDAD DE SALAMANCA 
Marta Teixeira Anacleto

Sara Augusto

Zulmira Santos

Coordenação

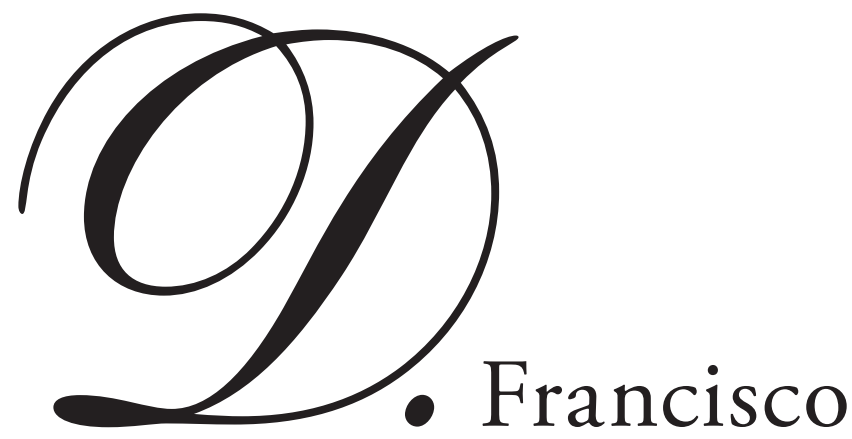

Manuel de Melo e o Barroco Peninsular

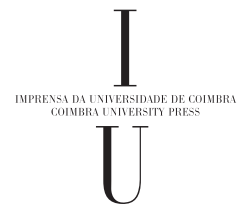


PARTE I

FORMAS E IMAGINÁRIO(s) DO BARROCO 


\author{
Ángel Marcos de Diós \\ Universidade de Salamanca
}

\title{
A UNIVERSIDADE DE SALAMANCA E PORTUGAL NO PERÍODO BARROCO
}

Tratar da Universidade de Salamanca e Portugal é enunciar também uma realidade condicionada politicamente: Portugal foi e é um país, com um território, administração, cultura, etc., ao passo que a universidade salmantina, sem ser (evidentemente) um país, é um reflexo de um outro país, com frequência em confronto com aquele de que se tornou independente no século XII. E, com efeito, para além dos períodos de pacífica conveniência e convivência, os avatares políticos de Portugal como nacionalidade marcam as suas relaçôes com a Universidade do Tormes. Ainda que se possa dizer que, até 1640, Salamanca nunca foi uma universidade estrangeira para os portugueses, a presença (mas sobretudo a ausência) deles nesta instituição dependeu quase exclusivamente desses avatares. Contando com o facto de faltarem três séculos de documentação no arquivo universitário (desde a fundação da instituição salmantina em 1218 até ao século XVI), pode-se comprovar esta afirmação a partir do momento em que se conserva sistematicamente essa documentação, isto é, a partir de meados do século XVI ${ }^{1}$.

Para o período que nos ocupa, nas relaçóes Universidade de Salamanca - Portugal, é fundamental a data de 1580. A anexação de Portugal por parte de Filipe I significa o livre acesso dos portugueses às aulas salmantinas, acesso muito condicionado desde que a universidade portuguesa se instaura definitivamente em Coimbra, em 1537. Com efeito, tanto D. João III e D. Sebastião como as autoridades académicas coimbrãs procuraram, por diferentes meios, impedir a saída dos lusitanos para outras universidades, especialmente para a salmantina (a mais desejada por proximidade, prestígio, tolerância com os judeus, etc.). Tendo em vista atrair os seus súbditos, D. João III, para além de adoptar o modelo estatutário salmantino e de criar uma universidade de orientação também fundamentalmente jurídica, entre 1537 e 1554 contratou três dezenas de professores, portugueses e espanhóis, graduados por Salamanca (para além de alguns de outras universidades, como Alcalá).

\footnotetext{
${ }^{1}$ É por isso que nunca poderemos saber, por exemplo (entre outros vários casos), a repercusão, quanto ao número de lusitanos nesta Universidade, da crise dinástica de 1383-85 de Portugal, porque até ao século XVI toda a documentação fica reduzida aos Libros de Claustro 1, 2 e 3, que abrangem o período 1464-1481.
} 
Esta medida magnânima de D. João III não produziu o efeito de atrair a maioria dos lusitanos que estudavam fora do reino, e, passado um tempo, as circunstâncias fazem mudar de parecer o rei, que começa a praticar a política contrária, com dificuldades e ameaças para os portugueses que estudavam ou obtinham graus noutras universidades. Política continuada, por outro lado, por D. Sebastião e pelas próprias autoridades universitárias coimbrãs ${ }^{2}$. A pouca efectividade dessas medidas fica patente no facto de que, como se verá, comparativamente, o número de escolares portugueses nas aulas salmantinas foi maior no período 1550-1580 do que na Monarquia Dual. Este interesse também tem muito a ver com o período de esplendor do Estudo salmantino, esplendor que começou a decair no último quartel do século XVI.

Se considerarmos como período de vigência do Barroco desde os fins do século XVI e todo o século XVII (é a opinião mais comum hoje), comprovamos que tal período inclui os sessenta anos da Monarquia Dual. Devido, sobretudo, ao desaparecimento de qualquer entrave administrativo com a chegada ao poder de Filipe I, pensaríamos que esta teria sido a época mais fecunda dos portugueses em Salamanca. Estudos posteriores têm-nos revelado - com a documentação do arquivo universitário salmantino na mão - que, quanto ao número de escolares - e também de vultos importantes -, foi mais notável, como acabamos de afirmar, o período de 1550-1580: enquanto no período filipino o número de lusitanos em Salamanca se aproxima dos dez mil, entre 1550 e 1580 ultrapassa o número de cinco mil (ainda que na maior parte da década de cinquenta a documentaçáo apenas nos permitiu identificar alguns portugueses, quando sabemos que deve ter havido centenas de estudantes oriundos de Portugal $)^{3}$.

Esboçaremos algumas das razóes, que em nosso entender são tanto académicas como políticas, desta menor frequência: nos fins do século XVI a Universidade do Tormes começava a perder o prestígio de que tinha sido detentora durante os séculos XV e XVI; os jesuítas fundam, em 1559, a Universidade de Évora, que, ainda que limitada às faculdades

\footnotetext{
${ }^{2}$ A fuga de escolares da universidade conimbrigense para outras universidades (principalmente Salamanca) chega a tal ponto que, em 1541, D. João III proíbe os portugueses de receber graus noutras universidades (Mário Brandão, Documentos de D. João III. Coimbra: Universidade de Coimbra, vol. II, 1937, pp. 67-68, doc. CCVI). Este facto elucida-nos sobre a real situação de êxodo, anterior a 1537, dos portugueses ao Estudo de Salamanca, sobretudo nos períodos em que a universidade portuguesa esteve sediada em Lisboa e quando ainda não se tinha renovado cientificamente. As dificuldades administrativas dos reis e das autoridades universitárias conimbrigenses visavam sobretudo a Universidade de Salamanca. Citamos alguns casos paradigmáticos: Frei Diogo de Murça, em carta ao rei (12-VIII-1550), declara que «os estudantes de Medicina se váo os mais delles graduar de bacharees a Salamanca, e isto como tem dous ou tres annos de Medicina». O Claustro da Universidade de Coimbra trata (14-VI-1556) «sobre os estudantes que estam em Salamanca para virê cotinuar seus estudos a esta vniuersidade» (A.U.C., Conselhos, vol. 3, f. 316v., publicado por Teixeira de Carvalho, "A anatomia em Coimbra no século XVI", in Revista da Universidade de Coimbra, III. Coimbra: 1914, 265, doc. 25). Um decreto real (6-XI-1564) ordena que "os Portugueses que estudão em Salamanca venhão a Coimbra» (A.U.C., Livro $1^{\circ}$ das provisóes, f. 190, publicado por Duarte Nunes de Lião, Leis Extravagantes, P. III, Ley XVI, pp. 583-584). Uma carta de D. Sebastião (28-II-1575) dispone «que todos os estudantes naturaes destes Reynos que estudão nas Universydades de Salamanqua, \& Alcallá, se venhão a Universydade de Coimbra dentro de hum anno» (A.U.C., Ibidem, f. 258).

${ }^{3}$ Como se verá, a decadência da universidade salmantina do Barroco também está reflectida nos professores e estudantes portugueses de prestígio. Entre 1550 e 1580, perto de uma vintena de portugueses exerceram como professores, alguns deles reconhecidíssimos catedráticos, entre os quais sobressai a conhecida tríade de civilistas que ocuparam a cátedra de Prima de Leis durante quase toda a metade do século XVI (Manuel da Costa, Aires Pinhel e Heitor Rodrigues).
} 
de Artes e Teologia, acolheu um importante número de portugueses (também de espanhóis) em detrimento da instituição salmantina, para além de que que as relaçóes entre a universidade salmantina e a Companhia sempre foram tensas ${ }^{4}$; a anexação de Portugal em 1580 começa a cavar uma profunda clivagem, que se vai agravando nos séculos seguintes, entre a sociedade espanhola e portuguesa, apenas mitigada nos nossos dias.

Oferecemos agora umas tábuas de frequências quinquenais entre 1580 e 1700: a primeira coluna refere-se aos escolares lusitanos matriculados em Salamanca (inclui também os inscritos em Gramática e Artes) e a segunda aos matriculados em Coimbra (incluídos gramáticos e artistas) $)^{5}$. Em ambos os casos, falamos em matrículas e não em escolares, porque, com alguma frequência, um mesmo aluno se matriculava duas vezes no mesmo ano.

\begin{tabular}{|c|c|c|c|}
\hline $1581-1585$ & 656 & matrículas & 878 \\
\hline 1586-1588 & 771 & “ & 1049 \\
\hline $1592-1595$ & 712 & “ & 1201 \\
\hline 1597-1599 & 546 & “ & 1109 \\
\hline $1604-1605$ & 408 & “ & 913 \\
\hline $1606-1610$ & 418 & “ & 988 \\
\hline $1611-1615$ & 626 & “ & 1037 \\
\hline $1616-1620$ & 664 & “ & 1113 \\
\hline $1621-1625$ & 735 & “ & 1073 \\
\hline $1626-1630$ & 662 & “ & 1291 \\
\hline $1631-1635$ & 564 & “ & 1007 \\
\hline $1636-1640$ & 493 & “ & 896 \\
\hline $1641-1645$ & 73 & “ & 930 \\
\hline $1646-1650$ & 19 & “ & 956 \\
\hline $1651-1655$ & 16 & “ & 1083 \\
\hline $1656-1660$ & 22 & “ & 1079 \\
\hline $1661-1665$ & 29 & “ & 962 \\
\hline $1666-1670$ & 54 & “ & 944 \\
\hline $1671-1675$ & 245 & “ & 1044 \\
\hline $1676-1680$ & 126 & “ & 1423 \\
\hline $1681-1685$ & 65 & “ & 1877 \\
\hline $1686-1690$ & 58 & “ & 1834 \\
\hline $1691-1695$ & 57 & “ & 1725 \\
\hline $1696-1700$ & 68 & “ & 1721 \\
\hline
\end{tabular}

\footnotetext{
${ }^{4}$ De facto, tanto em Salamanca como em Coimbra (na matrícula geral, isto é, sem ter em conta colégios seculares e religiosos) a Faculdade com menos estudantes foi Teologia.

${ }^{5}$ Nalguns casos, não se conservam os todos os livros de matrículas, por exemplo, entre 1596 e 1600. Há uma notável diminuição nos finais do século XVI e princípios do XVII devido à peste que assolou a Península. Por outro lado, náo se pode fazer uma comparaçáo rigorosa com os escolares de Coimbra, porque nos dados dessa Universidade, tirados dos estudos de António de Vasconcelos (Escritos vários. Coimbra: Publicações do Arquivo da Universidade de Coimbra, vol. II, 1988), não constam os escolares gramáticos nem artistas, enquanto em Salamanca efectivamente também estão incluídos. A comparação, pois, não é tão indicativa como desejaríamos. $\mathrm{O}$ caso de Évora é bastante diferente porque, por ter desaparecido a documentação dessa Universidade, não conhecemos o número de alunos que teve no período barroco.
} 
Fazendo uma comparação com a Universidade conimbrigense, não é necessário comentar como a partir de 1640 há um marcadíssimo "vazio» de portugueses em Salamanca. O mais curioso destes dados é que os quinhentos escolares que desaparecem de Salamanca com a Restauração não aparecem em Coimbra, o que confirma as nossas fundadas (como veremos) suspeitas de que a imensa maioria dos portugueses em Salamanca eram judeus ou cristãos-novos ${ }^{6}$.

Com estes dados e de modo genérico, podemos distinguir várias etapas nas relaçóes Portugal - Universidade salmantina do Antigo Regime: até 1640, presença muito numerosa de lusitanos nas aulas salmantinas ${ }^{7}$; 1640 , como não podia deixar de ser, significa um corte importante, porque quase desaparecem (mas não chegam a desaparecer) os lusitanos até ao tratado de paz com Castela (1662), momento em que se incrementa a matrícula. E, já fora do período Barroco, nos primeiros anos do século XVIII, por causa da Guerra de Sucessão em Espanha, assistimos, durante um tempo, ao seu completo desaparecimento; resolvido o problema da sucessáo, e nos anos centrais desse século, encontramos inscrita uma importantíssima plétora de lusitanos, sobretudo em Cânones, até que pouco depois das reformas iluministas do Marquês de Pombal (1772) desaparecerão definitivamente até aos nossos dias, nos quais, com os programas de Comunidade Europeia, se estabeleceu um intercâmbio recíproco (ainda que reduzido a algumas dezenas de estudantes).

${ }^{6}$ Os conflitos políticos e independentistas inverteram uma situação estável até 1640: é assim que passamos, por exemplo, dos 13,6\% de lusitanos no ano 1634-35 aos 1,4 em 1664-65, sem contar colegiais seculares ou religiosos (cf. Luis Enrique Rodríguez-San Pedro Bezares, «Declive y regionalización de la matrícula salmantina de los siglos XVII y XVIII", in Studia Historica, Universidad de Salamanca, vol. III, no 3, 1985, p. 187)

${ }^{7} \mathrm{O}$ elevado número deles desde a criação da Universidade salmantina revela-se, pelo menos em dois factos. Por um lado, desde os seus inícios aparecem portugueses nela; já nos Estatutos de 1242 (lembremos que foi criada por alvará de D. Afonso IX, em 1218), concedidos por Fernando, rei de Leão e Castela, aparece o primeiro lusitano, Miguel Peres o Pires, que formou parte do júri nomeado pelo próprio rei para resolver os conflitos entre os escolares e os moradores da cidade: «El obispo de Salamanca e el deán e el prior de los predicadores, e el guardian de los descalços e don Rodrigo e Pedro Guigelmo e Garci Gómez e Pedro Vellido e Ferrand iohannes de porto carrero e Pedro Munniz calonigo de leon e Miguel Pz calonigo de Lamego en los escolares e los de la villa mando esten por lo que estos mandaren" (Apud Vicente de la Fuente, Historia de las universidades, colegios y demás establecimientos de enseñanza en España. Madrid, vol. I, p. 89). Por outro lado, a importância e poder que desde muito cedo tinham conseguido os portugueses revela-se no facto de que, junto com outras sete (Campos, Extremadura, Galiza, Andaluzia, Mancha, Biscaia e Aragão), se constituíram em «nação» ou confraria. Por sua vez, estas oito "naçóes» se agrupavam em quatro turnos, que incluíam as seguintes dioceses (ou arquidioceses): o primeiro turno compreendia León, Oviedo, Salamanca, Zamora, Coria, Badajoz e Ciudad Rodrigo; o segundo, Santiago de Compostela, Astorga, Orense, Mondońedo, Lugo, Tuy e o reino de Portugal; o terceiro, Toledo, Sevilla, Cartagena, Córdoba, Jaén, Cádiz, Plasencia e Cuenca, e o quarto, Burgos, Calahorra, Osma, Sigüenza, Palencia, Ávila e Segovia e os reinos de Aragão e Navarra. No segundo turno, a Galiza, por um lado, e o reino de Portugal, por outro, tinham direito (e, de facto, o exerciam) ao seu conselheiro próprio: os conselheiros tinham importantes funçóes (académicas, sobretudo, enquanto que as dos deputados eram económicas), de entre as quais a mais ostentosa - mas náo a mais importante - era a eleição do reitor. Nas primeiras folhas dos Libros de Claustro aparece o conselheiro de cada "nação", que, no caso português, vem acotado (depois do nome e apelido) por fórmulas como «ex regno Portugaliae», "ex regno lusitano», "ex dioecese eborense», «mirandense», etc. Por uma circunstância muito especial (dois reitores ao mesmo tempo), no século XV, um português, D. Rodrigo Álvares, foi escolhido reitor pelos conselheiros na presença de D. Telmo, visitador da Universidade (cf. Florencio Marcos Rodríguez, Un cisma de rectores en la Universidad de Salamanca a fines del siglo XV, sep. de Salmanticensis, XIV, fasc. 2, Salamanca, 1967, pp. 341-369), quando, segundo os Estatutos, o reitor devia ser originário dos reinos de Castela ou Leão. 
Mas vamos centrarmo-nos no Barroco. A anexação filipina vai permitir aos portugueses ter o livre acceso à instituição salmantina porque significa não só a abertura da universidade salmantina aos lusitanos, sem pressóes coimbrãs, mas também, em certos casos, condiçóes muito favoráveis. Com efeito, Filipe I, pouco tempo após anexar Portugal, concretamente em 1581, vai promulgar um alvará a favor dos escolares naturais da diocese de Miranda do Douro $^{8}$, pelo qual os graus obtidos em Salamanca teriam validez em todo o território português, sem a obrigação de fazer equivalência na Universidade de Coimbra, como quase sempre foi preceptivo antes de 1580. Produz-se, a partir de este momento, um incremento dos escolares mirandenses, especialmente de escolares médicos ${ }^{9}$, numa região com pouca tradição médica.

Por outro lado, de entre as estrangeiras, no período Barroco e até 1640, a Universidade de Salamanca continua atraindo a maior parte dos portugueses que estudavam fora do país, como nos séculos anteriores. Depois do Concílio de Trento, Salamanca oferecia garantias de ortodoxia católica sobretudo com Filipe I, que, para evitar contaminaçóes heréticas, já em 1559 proibiu os seus súbditos de estudarem fora do reino, excepto na Itália. Acescente-se a isto o facto de que era a universidade da monarquia católica e a mais prestigiada no domínio do Direito (frente a Alcalá, eminentemente teológica), do qual

\footnotetext{
${ }^{8} \mathrm{O}$ tal alvará diz assim: "Que por esta cidade e termo estarem perto de Salamanca e desviada de Coimbra sua magestade aja por bem que hos naturaes dela usem de suas letras como se estudaraó em Coimbra estudando em Salamanca» (apud Francisco Manuel Alves, Anais. Ciclo da Restauração de Portugal. Lisboa: Academia Portuguesa da História, 1942, p. 105). Também em 1587, Filipe II (provavelmente com a mesma intenção que o alvará anterior) pôs limites à autoridade do mestre-escola da Universidade (uma figura universitária com vastíssimos poderes) que exercia também a sua omnímoda jurisdição sobre os escolares portugueses nas suas terras de origem: «Aluara sobre as cartas que meestre Escola da Universidade de salamanca passa para estes regnos. Quel Rey Faço saber aos que este aluara virem que sendo eu informado que o mestre escolla da see da cidade de salamanca nos meus regnos de castella, como juiz, E conseruador appostolico de Universidade de salamanca, a requerimento de alguns estudantes Matricollados na dita Uniuersidade, passaua Cartas para nestes regnos de portugal alguãs pessoas leguas naturaes, ou residentes nelles serem citados chamados, E requeridos pera o seu juizo, Mandey Ver por letrados do meu conselho, E meus desembargadores do paço se podra o dito mestre Escolla com direito passar às tais cartas, E dos que lhes pareceo me foi dada Rellação a qual vista per my, E as causas E razóes que appontaráo, E como vindo já per outras vezes em duuida nestes regnos se os Leigos citados pello dito conseruador deuiaó acodir a seu juizo, se julgou que naô eraó obrigados a isso por ser contra forma das leis delles. E minhas ordenaçoens, auendo eu A tudo Respeito, E por outras causas que me a isso mouem ey por bem, E mando que as pessoas leiguas assj naturaes destes regnos como quaisquer outras que nelles residirem, Naó possaô nestes ditos regnos ser citados Nem obedeçaó as cartas do dito mestre Escolla, Porque os chame a seu juizo; Nem se lhe guardem suas censuras, nem sentenças como juiz que nestes casos o naó pode ser nem tem jurisdiçaó alguá sobre os leigos e sendo caso que o dito mestre Escolla passe as cartas inhibitorias, E çitatorias para clerigos, ou pessoas outras Eclesiasticas, se naó fara pellas ditas cartas obra alguã sem primeiro mo fazer saber, ou ao meu gouernador destes regnos que pello tempo for, pera que as mande uer e informado bem do caso mande que se cumpraó, E guardem as tais cartas pareçendo que conforme a direito se deuem comprir E guardar como acerca disso esta deterMinado por minhas ordenaçoens e leis destes regnos $\mathrm{E}$ mande pera esso passar prouisaó, Pello que mando a todos meus desembargadores corregedores, ouuydores, juizes $\mathrm{E}$ justiças destes meus regnos $\mathrm{E}$ senhorias de portugal, E a Quaisquer outros officiaes E pessoas a que tocar, E pertencer que Em todo Cumpraó, E guardem, E façaó inteiramente comprir e guardar este meu aluará como nelles se contem» (A.N.T.T., Livro de Leis (1576-1612), f. 163v).

${ }^{9}$ Este privilégio específico expedido em favor dos naturais da diocese de Miranda do Douro era especialmente útil para os bacharéis médicos que, para poder exercer em Portugal, antes de este alvará eram obrigados a aprovar um exame de suficiência perante o físico maior do reino. Os não mirandenses sempre continuaram obrigados a fazer esse exame de suficiência.
} 
tanto precisava a crescente burocracia dos Áustrias. Não era estranho, portanto, que o comum dos portugueses, por tradição, por proximidade e por intereses profissionais, continuasse considerando Salamanca como a sua segunda universidade ${ }^{10}$.

Desde a sua fundação a Universidade de Salamanca (como a Universidade portuguesa a partir de 1537, quando se instala definitivamente em Coimbra) optou, fundamentalmente, pelos estudos de Direito. Assim, no século XVII, é também uma universidade de juristas (maioritariamente canonistas), com uma importante faculdade de Teologia e uns razoáveis estudos de Medicina, e uns apêndices de Matemática, Música e Astrologia, para além dos estudos de Artes, prévios ao ingresso nas faculdades de Teologia ou Medicina. Paralelamente, e conforme a importância das faculdades, foi aumentando o número de cátedras, tanto de propriedade como cursatórias, para além de que os salários dos professores eram mais elevados nas faculdades de maior prestígio. São estas pautas que seguem os escolares portugueses, com algumas importantes diferenças: o contingente maior envereda pelos estudos de Direito, poucos os teológicos por uma óbvia razão, em 1559 tinha sido criada a universidade jesuítica de Évora (com estudos de Artes e Teologia), que em 1590 já tinha por volta de 1600 escolares $^{11}$, para além de que os conventos religiosos salmantinos conferiam graus em Teologia. São estas as razóes pelas quais julgamos que os estudantes lusitanos de Teologia na universidade salmantina nunca significaram mais de $6 \%$ dos portugueses de Salamanca.

Em comparação com a universidade de Quinhentos, a do Barroco apresenta algumas particularidades. Apesar de a Corte ter uma universidade mais próxima (Alcalá), a instituição salmantina foi a universidade dos Áustrias, por representar o modelo ideológico da Espanha Imperial, patente, por exemplo, nas credenciais régias do visitador Ribera Báñez em 1653, onde se faz constar esta universidade como «Estudio general de la Cristiandad y maestra de la juventud de mis Reynos para los ministerios de la Religión, Govierno y Justicia» ${ }^{12}$. Deste modo, a universidade de Seiscentos (apesar da sua reconhecida ortodoxia) vai perdendo o carácter director pontifício para assentar-se sob a tutela da monarquia e sofrer as intromissóes régias, como a diminuiçáo da autoridade do mestre-escola, representante da autoridade eclesiástica. É sob esta perspectiva que se explicam os fastos dos nascimentos dos príncipes ou das visitas dos reis ou, como ocorreu em 1641-42, quando recebe os regedores urbanos que solicitavam apoios e compra de armas para a defesa dos ataques fronteiriços de Portugal.

O reitor continua a ser um estudante (da nobreza títulada), escolhido por eles e assessorado por um conselho consultivo (os conselheiros), que representava as diversas

\footnotetext{
${ }^{10}$ Lembremos que a Universidade de Évora apenas tinha as facultades de Artes, prévia e obrigatória para os estudos teológicos (e médicos), e a de Teologia.

${ }^{11}$ «Inaugurada oficialmente a 1 de Novembro de 1559, tinha já em Abril de 1560 cerca de 600 alunos, sendo da Companhia apenas pouco mais de 60. Seis anos mais tarde estavam matriculados 800, excluídos os alunos de ler e escrever. Em 1571 tinha 1000 alunos, oito anos mais tarde 1300 e, em 1592, atingiam os estudantes o número de 1 600" (História da Universidade de Coimbra, I vol., tomo II (1537-1771). Coimbra: Universidade de CoimbraFund. Calouste Gulbenkian, 1997, pp. 605-606).

${ }^{12}$ Apud Luis Enrique Rodríguez-San Pedro Bezares, "Barroco y tradicionalismo", en La Universidad de Salamanca. I, Historia y proyecciones, ed. de M. Fernández Álvarez, L. Robles Carcedo y L. E. Rodríguez-San Pedro Bezares. Salamanca: Ediciones Universidad de Salamanca, 1989, p. 103.
} 
confrarias ou «naçôes» (em número de oito, como já ficou dito: Galiza, Portugal, Campos -Castela-a-Velha e Leão-, Biscaia, Estremadura, Mancha (Castela-a-Nova), Andaluzia e Coroa de Aragão (Aragáo e Catalunha). Se bem que comecem a surgir, ao longo do século, diversas tensóes, sobretudo na eleição de reitor e conselheiros, e entre escolares e lentes, autoridades universitárias e municipais, etc, nalguns dos estamentos produz-se o que poderíamos denominar «aristocratização» dos poderes universitários, na qual começam a emerger os poderes dos docentes por oposição ao estamento dos discentes, principalmente os dos catedráticos de propriedade.

Quanto ao regime docente, a provisão de cátedras fazia-se, a exemplo de Bolonha, por votação directa dos escolares, o que deu lugar a corrupçóes e repetidas brigas entre os escolares das diferentes "naçóes», até que tal sistema foi definitivamente abolido em 1641, e substituído pela nomeação directa do Conselho de Castela, prévia avaliação dos concursos e curricula vitae; o que não resolveu o problema porque também as provisóes de professores começaram a ser controladas pelos colegiais maiores. Durante todo o século XVII ouve diferentes modos de provisão, nenhum dos quais se impôs definitivamente. No sistema de eleição directa dos escolares, os lusitanos tiveram até 1640 uma razoável importância no sentido de que, como as «naçóes» geralmente votavam por um candidato, entre as oito, a de Portugal era a segunda mais numerosa, mas já a bastante distância da de Campos (esta incluía as dioceses de Salamanca, León, Oviedo, Zamora, Coria, Badajoz e Ciudad Rodrigo). Estas rivalidades na provisão de cátedras tiveram grande transcendência nas relaçôes entre as diferentes nações. A portuguesa, neste século, poucas vezes logrou impor catedráticos (no século XVII apenas tiveram esta condição uma meia dúzia deles, enquanto no século anterior contam-se mais de uma vintena, alguns deles com grande sucesso, por exemplo, a cátedra de Prima de Leis, na segunda parte do XVI, foi da quase exclusiva responsabilidade dos portugueses $)^{13}$.

Deste modo, já entre os anos 30 e 40 assistimos a uma degradação da vida universitária, patente também no ditado nas aulas (herdado do século anterior e que favoreceu a preguiça dalguns sectores do professorado com o trespasso de apontamentos), abandono das aulas por parte dos estudantes, excesso de festas e absentismo escolar (também de professores), ausência de visitas às cátedras; e quanto às ordens religiosas, a vinculação das cátedras de Teologia (sem concurso) por parte dos dominicanos já em 1606 e 1608, e, por esta razão, a ameaça das outras ordens religiosas de abandono da Universidade se não se lhes concediam as mesmas regalias. Já desde os finais do século anterior tinha decaído enormemente o número dos matriculados em Gramática (por causa fundamentalmente das escolas de latinidade regentadas pelos jesuítas - que se especializam no ensino das primeiras letras - e da criação de escolas municipais em povoaçóes de mais de 500 fogos) e, neste, verificar-se-há um acusado decréscimo em Artes e Teologia. Os colégios maiores (S. Bartolomeu, Oviedo, Cuenca e Arcebispo) com dificuldades eram submetidos às

${ }^{13} \mathrm{Na}$ prática, com frequência, não podiam defendê-los com garantias (no fundo, não deixavam de ser estrangeiros): Aires Barbosa, o Mestre Grego (aluno preferido de Nebrija e o provável autor da famosa fachada plateresca da universidade) perdia a cátedra de Prima de Gramática em favor de Pedro de Espinosa; Pedro Margalho concorreu em 1526 contra Francisco de Vitoria; Heitor Pinto contra Frei Luís de Leão..., todos eles com resultados negativos. 
directrizes régias, conferindo graus e ignorando os seus estatutos, quanto ao ingresso..., para além de que, progressivamente, se vão apoderando dos órgãos de decisão da universidade. É assim que começa a consolidar-se a universidade dos colégios (desde $12 \%$ da matrícula nos inícios do século até aos 50\% no final), consolidação que continuará acentuando-se no século XVIII.

Continua a decadência durante todo o século e assistimos, assim, a uma degradação da atmosfera intelectual, que desemboca num flagrante imobilismo perante as novas correntes de pensamento, ainda que náo faltem exemplos de inquietude intelectual, sendo um dos mais notáveis o português Luís Rodrigues Pedrosa ${ }^{14}$.

As diferentes faculdades começam a perder peso conforme avança o século. Como sempre tinha acontecido, eram os juristas os que acaparavam números e poder na universidade salmantina de Seiscentos. As faculdades jurídicas já não gozam do prestígio do século anterior e, ainda que os graduados em Cânones e Leis não encontrem os ofícios de promoção burocrática com facilidade, continua a ser a Universidade dos Áustrias; do mesmo modo que, no campo da Teologia, a Universidade do Tormes manifesta o seu domínio na provisão de altas dignidades e cargos eclesiásticos: «Durante el siglo XVII, los obispos de los reinos de León y de Castilla habían cursado proporcionalmente en las siguientes universidades: Salamanca $(27,7 \%)$, Alcalá $(9,4 \%)$, Valladolid $(15,5 \%)$, y el resto en otras menores. La alta nobleza, no obstante, fue desapareciendo progresivamente: en el curso de 1639-1640 había en Salamanca 10 segundones de la Grandeza y 14 Titulados, mientras que en el último cuarto del siglo no aparece referencia alguna, porque las élites habían abandonado el interés por la formación universitaria y la suplían con preceptores particulares» ${ }^{15}$.

Já nem se fale, neste sentido, dos lusitanos: no período barroco apenas descobrimos dois bispos antigos escolares (e, ainda, no fim do século XVI): D. Martim Afonso Foito, bispo de Leiria, Lamego e Coimbra e secretário de Estado em Madrid, e D. Manuel Afonso da Guerra, bispo de Cabo Verde ${ }^{16}$, e um nobre da Grandeza (um filho do Conde

\footnotetext{
${ }^{14}$ Luís Rodrigues Pedrosa foi um dos grandes mentores das ideias inovadoras na Universidade salamantina do Barroco: "Que los catedráticos salmantinos de Teología e Matemáticas no fueran copernicanos primero ni newtonianos después no quiere decir que no fueran científicos y menos que no fueran competentes en su modelo epistemológico. A pesar de las trabas inquisitoriales y mentales, muchos de ellos conocían lo que ocurría al otro lado de las fronteras, aunque no lo compartieran. Es el caso de Luís Rodrigues de Pedrosa (1599-1573), catedrático de Medicina y Filosofía natural, quien no sólo conocía perfectamente las teorías de científicos como Copérnico, Tycho Brahe o Descartes, sino que también aceptaba ciertas ideas y las publicaba (Selectarum Philosophiae e medicinae difficultatum, 1666) o las defendía en unas clases que gozaban de una enorme aceptación y popularidad, como demuestra el hecho de que asistieran a ellas dignidades, magistrados e incluso el obispo de la ciudad. Pedrosa anticipaba así el movimiento de los novatores y nos previene contra generalizaciones apresuradas» (Ángel Weruaga Prieto, Lectores y bibliotecas en la Salamanca moderna (1600-1789). Salamanca: Junta de Castilla y León, 2008, pp. 184-185).

${ }^{15}$ Luis Enrique Rodríguez-San Pedro Bezares, op. cit., pp. 137-139.

${ }^{16}$ Enquanto durante o resto do século XVI, pelo menos, conhecemos D. Sancho Pires, bispo do Porto; D. Nuno Álvares, bispo de Angra; D. Diogo de Sousa (também foi estudante em Paris), arcebispo de Braga; D. Manuel de Sousa, bispo de Silves e arcebispo de Évora; D. Gonçalo Pinheiro (também estudante em Paris), bispo de Safim, embaixador na França e bispo de Viseu; D. Jerónimo Osório, bispo de Silves; Frei Bernardo da Cruz, bispo de Santo Tomé; D. Pedro Fernandes Sardinha, primeiro bispo do Brasil.
} 
de Faro) e outros dois possíveis ${ }^{17}$. Quanto ao professorado, foram poucos os lusitanos que exerceram o seu magistério na Alma Mater salmanticense (ou noutras universidades): para além do já referido Luís Rodrigues Pedrosa, Fernando Aires de Mesa, escolar em Salamanca e Coimbra e catedrático em Salamanca; Francisco Homem de Abreu, que depois de ensinar Gramática e Retórica em Ledesma e Salamanca, foi catedrático de Latim na universidade salmantina; António Camelo Pinto, catedrático de Cânones em Coimbra; João Velasques Altamirano; Frei Serafino de Freitas, em Valhadolid... e poucos mais.

Também não parece terem produzido muitas obras jurídicas ou teológicas... E quanto à literatura, os planos de estudo da universidade do Antigo Regime pouco ajudavam à formação de literatos: a literatura interessava segmentos muito reduzidos da sociedade ${ }^{18} \mathrm{e}$, por isso, apenas produziu literatos de segunda ou terceira categoria: prosistas, como António Mendes ou João Salgado de Araújo; poetas, como António Raposo, Domingos Antunes Portugal, Francisco de França da Costa, João Sucarelo Claramonte.... Sim, produziu alguns conhecidos advogados (Amador Rodrigues, Jacinto Álvares de Almeida), algum comentarista das Sagradas Escrituras ou Teologia (Francisco Fernandes Prata), corregedores, juízes..., mas sim (como acontecera no século anterior) importantes médicos (Zacuto Lusitano, André António de Castro, António da Mata Falcão).

Por outro lado, e como desvantagem suplementar para Salamanca, a Monarquia Dual propiciou que a corte atraísse ilustres portugueses (un caso paradigmático é o de Faria e Sousa): durante o reinados dos Filipes o Colégio de Santo Ildefonso de Alcalá albergou um notabilíssimo número de portugueses, mais dos que reuniam todos os salmantinos em conjunto ${ }^{19}$.

O século XVII significa, em conjunto, uma época convulsa e confusa (em muitos casos) quanto à clarificacão dos limites de quanto rodeava a vida universitária (reitor, mestre-escola, conselheiros, deputados, colégios, claustros, etc.): uma desagregação dos poderes bem delimitados do século anterior. E neste contexto, os portugueses pouco tinham a dizer pela descontínua matrícula durante todo o século (como já vimos, peste nos inícios, alternativas conforme a situação política..., com uma presença residual durante

${ }^{17}$ Também é verdade que os nobres procuravam para os seus filhos segundos ou bastardos mestres particulares, livres dos perigos da tumultuosa vida universitária. Era, por isso, o terceiro estado o que maioritariamente nutria a universidade, sobretudo a burguesia (apenas uma parte sabia ler), cujas preferências estavam encaminhadas a um lugar na burocracia do Estado: administradores (em casas nobiliárias, mosteiros, abadias, etc.), tabeliōes, corregedores, juízes, etc., eram lugares muitao desejados pelos titulados universitários. Por outro lado, durante o Barroco começou a banalizar-se o título de «dom» em toda a Península e por isso alargou-se consideravelmente o número desses intitulados. Se durante o século XVI, apenas 0,1 \% dos portugueses era intitulado de D., no século XVII já são 5\% (e no XVIII já $15 \%$ ), ainda bastante inferior à média dos espanhóis. Ainda assim temos que concluir que se «en principio, el 'don' debía suponer un indicativo de nivel de nobleza superior a la simple hidalguía», a nobreza portuguesa frequentava minimamente a Universidade de Salamanca.

${ }^{18}$ Consultámos pormenorizadamente os opúsculos de António de Oliveira, A livraria de um teólogo do século XVI (Coimbra: 1964); A livraria de um canonista do século XVI (Coimbra: 1966); A livraria de um canonista do século XVII (Coimbra: 1967), e entre centenas de títulos, apenas encontrámos uma dúzia de obras humanísticas (nem mesmo literárias), fora das profissionais. Observam-se as mesmas tendências com os inúmeros inventários que já se fizeram em Espanha.

${ }^{19}$ Cf. Joaquim Veríssimo Serrão, "Contributo para o estudo dos portugueses na Universidade de Alcalá (1509-1640)», in Revista Portuguesa de História, 17. Coimbra: 1978, pp. 37-54. 
uma boa parte da segunda metade) e pela reduzidíssima presença nos colégios. Na verdade, a época de ouro dos portugueses em Salamanca foram os três primeiros quartéis do século XVI (a falta de documentação não nos ajuda, mas também brilharam escolares portugueses da universidade salmantina do último quartel do século XV), período que coincide também com a época de esplendor da própria Universidade: houve mais lentes lusitanos no período $1550-1580$ do que durante todo o período barroco ${ }^{20}$.

Pelas causas apontadas e por outras que nos escusamos de pormenorizar, no decorrer do período barroco na universidade salmantina desce drasticamente a matrícula conforme avança o século XVII: nos inícios do século matriculavam-se por volta de 5000 alunos e nos fins apenas 2000. Na verdade, têm-se apontado diferentes causas, que não conseguem explicar estes fraquíssimos números no fim de século. Para além de que, como já ficou dito, se tinha reduzido consideravelmente a matrícula dos gramáticos. Mas a faculdade mais afectada por este decréscimo foi a de Teologia, possivelmente pela fuga dos regulares para os seus próprios conventos, e, no caso específico dos lusitanos, também pela influência da Universidade de Évora, criada pelos jesuítas (cujas relaçóes com a universidade salmantina sempre foram tensas, ainda que alguns desses fundadores provinham do colégio salmantino da Companhia) e que aglutinava um grande número de escolares teólogos.

O mais curioso é que quando em 1640 desaparecem os portugueses de Salamanca (uma média de mais de quinhentos até 1640) não sobe significativamente a matrícula em Coimbra. E assim o que críamos um grande intercâmbio de escolares entre Salamanca e Coimbra não foi tão intenso como se deveria supor entre duas universidades tão próximas e com vinculaçóes científicas paralelas. É por isso que, como mais à frente se verá, pode confirmar-se a nossa hipótese de que a maior parte dos lusitanos em Salamanca eram judeus ou cristãos-novos ${ }^{21}$.

Para além da já referida instabilidade organizativa e da degradada atmosfera intelectual, comum a todos os escolares, os portugueses sofriam de outras circunstâncias adversas, a principal das quais relacionada com o facto de grande número deles serem judeus e cristãosnovos. Para além de outras razóes, uma das principais para a sua vinda a Salamanca foi consequência da dura perseguição que sofreram em todo o território português durante décadas, mas mais evidente em Coimbra pela transcedência que tiveram os processos inquisitoriais contra distinguidos professores da Universidade e conhecidas dignidades da Sé, sobretudo em finais do século XVI e na segunda e terceira década de XVII (entre eles os doutores André de Avelar - num segundo processo -, Manuel Rodrigues Navarro, António

\footnotetext{
${ }^{20}$ Em primeiro lugar, é possível que o campo onde mais se distinguiram tenha sido o do ensino (tanto na Universidade salmantina como depois muitos deles, antigos professores ou mesmo alunos, também na conimbrigense), sendo de destacar a conhecida tríade de civilistas (Manuel da Costa, Aires Pinhel e Heitor Rodrigues), que na segunda metade do século XVI ocuparam ininterruptamente a cadeira de Prima de Leis. Nestes trinta anos objecto do nosso estudo, uma dúzia de portugueses exerceram como catedráticos na Universidade do Tormes. Catedráticos, pois, foram: Aires Pinhel (Leis), Ambrósio Nunes (Medicina), Francisco Martins (Gramática), Francisco de Salazar (Latín), Heitor Rodrigues (Leis), Henrique Fernandes (Artes), Luís de Lemos (Medicina), Manuel da Costa (Leis), Miguel da Costa (Cânones), Vasco Fragoso (Gramática), etc.

${ }^{21}$ Relativamente a Évora, não podemos avançar hipóteses muito fiáveis, porque desapareceu a maior parte da documentação; mas são poucas as dezenas de escolares que, na sua matrícula em Salamanca, dizem ter recebido graus nessa Universidade.
} 
Gomes y António Homem² ${ }^{22}$. Na realidade, os cristãos-novos tinham-se situado em posiçôes de privilégio: no já referido processo de André de Avelar (1620), são descobertos como judaizantes um grande número de cónegos e freiras ${ }^{23}$. Segundo J. Lúcio de Azevedo, em 1646 todas as dignidades da Sé-Catedral de Lisboa eram cristãos-novos ${ }^{24}$. Estes são alguns dos muitos indícios que poderíamos aduzir. A riqueza dos conversos movia e removia montanhas, coraçóes e cargos, e até nos colégios maiores, cujos estatutos proibiam expressamente a entrada aos que náo apresentavam provas de limpeza de sangue, depois das pertinentes informaçôes, entravam os cristãos-novos ${ }^{25}$. De facto, os portugueses (todos e não apenas os escolares médicos) publicamente eram chamados $« j u d e u s{ }^{26}$.

Como veremos a seguir, é possível verificar que, quando proliferam os processos inquisitorias em Portugal, sobe a matrícula de lusitanos em Salamanca, particularmente na faculdade de Medicina (sobretudo na década de 1620-30).

É no período filipino que as percentagens de portugueses nesta faculdade sobem de forma substancial. Ainda que essas percentagens de lusitanos (em relação a todos os inscritos nessa faculdade) sempre foram muito superiores à média, neste período encontramos números inimagináveis, de tal maneira que nalguns anos o número de inscritos portugueses ultrapassou, em números absolutos, o de espanhóis. Isto acontece no ano 1633-34, no qual entre 108 incriçóes, 69 correspondem a portugueses ${ }^{27}$. Deve-se esta progressão a dois

${ }^{22}$ Cf. a documentada tese de doutoramento, dactilografada, de João Manuel Brito Saraiva de Carvalho, apresentada na Universidade de Coimbra em 1994, «Inquisiçấo e Universidade. A confraria de S. Diogo», que teve a deferência de nos oferecer (e que aqui publicamente agradecemos), fundamental para estudo do processo do Dr. António Homem, para além de inúmeras notícias, em primeira mão, sobre os judeus e cristãos-novos de Coimbra.

23 "[André de Avelar] foi preso em Março de 1620, em Coimbra, tendo sido denunciado por Crispim da Costa '...Cónego' [...] Em 21 de Março André de Avelar foi chamado a depôr e confessou de imediato, acusando homens como: Mateus Lopes, cónego e cristão-novo; o dr. António Homem, cónego na Sé e meio cristão-novo; Miguel Gomes, o Manco, cristão-novo preso nestes cárceres; Francisco, prebendeiro da dita Sé, entre outros» (Maria de Deus Beites Manso, «O segundo processo na Inquisição do mestre André de Avelar (1620-1622)», em Universidade(s). História Memória Perspectivas, ed. cit., p. 285). O próprio André de Avelar «além de ser professor de Matemática, foi igualmente Tercenário da Sé, Sacerdote, Guarda da Livraria e do Cartório, etc.» (id., ibid., p. 281).

${ }^{24}$ Carta do P. Nuno da Cunha a D. João IV (10 de junio de 1647), Corpo Diplomático Português, 13o 515 (cf. João Lúcio de Azevedo, História dos cristãos-novos portugueses. Lisboa: Livr. Clássica Editora, 1921, p. 153).

${ }^{25}$ Cf. Baltasar Cuart Moner, entre outros casos exemplares de judeus e cristãos-novos (referidos a espanhóis), estuda o de Juan de Mendoza, colegial de S. Bartolomeu entre 1508 e 1514: «Nobleza y élites conversas: Los Novo y los Mendoza de Jaén en una documentación salmantina del siglo XV", in Salamanca. Revista de Estudios, 42. Salamanca: 1999, pp. 15-42. Repare-se que, neste caso, se trata de um colegial do século XV, quando a perseguição dos judeus ainda não era táo virulenta como nos século XVI e XVII.

${ }^{26}$ Vejamos um documento extremamente elucidativo: «14 noviembre 1633. Este día ubo una pendençia muy sangrienta entre los Portugueses y vizcaínos, por auer salido las noches preçedentes a colearse unos a otros y preçipue porque los vizcaínos trataron de judíos a los Portugueses» (Biblioteca Universitaria de Salamanca, Diarios de la Compañía de Jesús, años 1620 a 1641, ms. 576, f. 162).

${ }^{27}$ Se compararmos com o número total de escolares médicos, comprovamos que em 1579-80 os portugueses constituem 26\%; 36\%, em 1597-98 (em 1596 a Universidade de Coimbra modificou os estatutos e exigiu seis anos para o bacharelato em Medicina frente aos quatro Salamanca); em 1600-04, são 32\% (a peste de fins de século retraiu a ida de portugueses a Salamanca); 1607-07 recupera esses 36\%; o ano 1612-13, com 44\%, consolida essa subida, que se mantém por volta de $50 \%$ até 1640 , excepto nalguns anos como $1633-34$, com uma percentagem de $64 \%$ de lusitanos (69 matrículas entre 108 no total). 
factores fundamentais: o requisito da universidade coimbrã, desde o ano 1596, de cursarem seis anos de Medicina (para além dos três de Artes) para obter o título de bacharel frente aos quatro de Salamanca; e, sobretudo, a imunidade de que gozavam em Salamanca relativamente à perseguição inquisitorial ${ }^{28}$. Este segundo aspecto adquire especial relevância, como já se viu, sobretudo a partir da segunda década de XVII ${ }^{29}$.

Tendo em conta os dados dos livros de matrículas das universidades de Salamanca e Coimbra, houve mais escolares portugueses de medicina na cidade do Tormes do que na do Mondego ${ }^{30}$. Vejamos o que nos mostra a seguinte ordenaçáo (quinquénios, escolares médicos portugueses em Coimbra e escolares médicos portugueses em Salamanca):

\begin{tabular}{lll}
$1579-1584$ & 52 & 38 \\
$1584-1589$ & 45 & 49 \\
$1589-1594$ & 61 & 64 \\
$1594-1599$ & 81 & 67 \\
$1599-1604$ & 66 & 65 \\
$1604-1609$ & 68 & 54 \\
$1609-1614$ & 62 & 63 \\
$1614-1619$ & 66 & 85 \\
$1619-1624$ & 66 & 78 \\
$1624-1629$ & 70 & 76 \\
$1629-1634$ & 68 & 81 \\
$1634-1639$ & 65 & 55 \\
\hline Percentagens $^{31}$ & 64,17 & 64,58
\end{tabular}

Também não é estranho, portanto, que os primeiros médicos nascidos no Brasil (pelo menos, Miguel Carvalho, Francisco de Fonseca, Bernardino Pessoa de Almeida, todos do século XVII) se tenham formado em Salamanca e não em Coimbra ${ }^{32}$.

\footnotetext{
${ }^{28}$ Portugal nâo tinha tratado de extradição com Castela. Por outro lado, até agora não se encontrou qualquer denegação de inscrição por não ter limpeza de sangue. Só sabemos de um caso de demora administrativa (isso sim, referido a um português): trata-se de Francisco Dias, natural de Vinhais, que «después de ser aprobado en su examen por unanimidad, los examinadores 'todos unánimes' acordaron que, por haber sido preso, detenido y encarcelado por mandato del Santo Oficio, no se le diese el grado de bachiller en Medicina hasta que constase con toda claridad ser hábil y capaz de dicho grado»; deste modo, teve que apresentar junto do reitor (24-3-1571) um testemunho de não ter sido inabilitado pela inqusição para receber tal grau (cf. Teresa Santander, Escolares médicos en Salamanca (Siglo XVI). Salamanca: 1984, pp. 33 e 160).

${ }^{29}$ Cf. supra, notas 22 e 23.

${ }^{30}$ Os dados referidos a Salamanca são da nossa responsabilidade, enquanto os relativos a Coimbra podem ser consultados em António de Vasconcelos, op. cit., pp. 120-121.

${ }^{31}$ Alguma coisa de semelhante se passa na faculdade de Cirurgia (sempre com muito poucos inscritos; nalguns anos apenas houve portugueses), criada en 1595, e cuja matrícula aparece separada da de Medicina a partir de 159798. Por isso, quando falamos de médicos, implicitamente também estamos a falar de cirurgiōes.

${ }^{32}$ Cf. Ángel Marcos de Dios, «Estudiantes del Brasil en la universidad de Salamanca durante los siglos XVI y XVII», in Revista de História, 105. São Paulo: 1976, pp. 215-230.
} 


\section{Conclusôes}

Desde já, uma constatação importante: pela documentação que se conserva no arquivo universitário, a Universidade de Salamanca, até 1640, nunca foi uma universidade propriamente estrangeira para os portugueses.

De tal modo que, apesar da decadência em que se tinha sumido a universidade do Tormes no Barroco, os portugueses continuaram a frequentá-la com grande sucesso, e a não ser por uma causa política de grande relevo, como foi a Restauração, a Universidade de Salamanca teria continuado a ser a preferida de entre as estrangeiras. Ainda assim, e até às reformas pombalinas (1772), nos períodos de relaçóes políticas de amizade, todos os anos a frequentavam bastantes dezenas (quando não centenas) de alunos oriundos de Portugal.

Parece confirmar-se a hipótese de que a imensa maioria dos escolares lusitanos em Salamanca eram de ascendência judia, sobretudo os estudantes de Medicina.

Se juntarmos os escolares de Coimbra, de Évora e de Salamanca até 1640, é necessário admitir que Portugal possuiu uma das populações mais cultas da Europa ou, pelo menos, das mais universitárias ${ }^{33}$.

Por todas estas razóes, podemos enunciar um asserto de muita maior transcendência: a inegável influência da Universidade salmantina na cultura portuguesa.

${ }^{33}$ Tomando como base de cálculo o método que aplica Richard R. Kagan para as universidades de Castela (Universidad y sociedad en la España moderna. Madrid: Tecnos, 1981, pp. 244-245), parece que os varốes de dezoito anos constituíam $1 \%$ mais ou menos da população de um país da Europa cristã nessa época. Portugal durante o período filipino podia ter uma população de 1300000 pessoas (Joaquim Veríssimo Serrão, "Uma estimativa da população portuguesa em 1640", sep. das Memórias da Academia das Ciências, vol. XVI. Lisboa: 1975, p. 217): $1 \%$ de $1300000=13000$ jovens de 18 anos. Se a população universitária portuguesa em 159293 (ano do qual conhecemos dados certos nas três universidades) era, em conjunto, de 3501 escolares (Coimbra, 1200; Évora, 1600, e Salamanca, 700), e dividimos esses 3501 escolares por quatro anos de média de um estudante na Universidade, os escolares portugueses que entravam cada ano na Universidade seriam 875: 875/13 $000=6,73 \%$, uma percentagem altíssima, se compararmos com Castela $(5,43 \%)$ ou a Inglaterra do século XVII (2,5\%), o que significaria a populaçáo mais culta da Europa. Estes cálculos, que devem ser tomados com as devidas reservas, dão, no entanto, uma ideia do desenvolvimento cultural de Portugal nos fins do século XVI. 
Série

Documentos

Imprensa da Universidade de Coimbra

Coimbra University Press

2010

- U

C • 